

\title{
Effect of process variables on wastage in fluidized bed combustors: criteria for test procedures
}

John Stringer, Stuart Macadam, Ian Wright, Vijay Sethi

\section{To cite this version:}

John Stringer, Stuart Macadam, Ian Wright, Vijay Sethi. Effect of process variables on wastage in fluidized bed combustors: criteria for test procedures. Journal de Physique IV Proceedings, 1993, 03 (C9), pp.C9-797-C9-805. 10.1051/jp4:1993983 . jpa-00252425

\section{HAL Id: jpa-00252425 https://hal.science/jpa-00252425}

Submitted on 1 Jan 1993

HAL is a multi-disciplinary open access archive for the deposit and dissemination of scientific research documents, whether they are published or not. The documents may come from teaching and research institutions in France or abroad, or from public or private research centers.
L'archive ouverte pluridisciplinaire HAL, est destinée au dépôt et à la diffusion de documents scientifiques de niveau recherche, publiés ou non, émanant des établissements d'enseignement et de recherche français ou étrangers, des laboratoires publics ou privés. 


\title{
Effect of process variables on wastage in fluidized bed combustors: criteria for test procedures
}

\author{
John Stringer $\left({ }^{1}\right)$, Stuart S. MacAdam $\left({ }^{2}\right)$, Ian G. Wright $\left({ }^{3}\right)$ and Vijay K. Sethi $\left({ }^{4}\right)$
}

(1) EPRI, 3412 Hillview Avenue Palo Alto, California 94303 U.S.A.

(2) Lawrence Berkeley Laboratory, University of California, Berkeley, California, U.S.A.

$\left({ }^{3}\right)$ Battelle Columbus Laboratories, 505 King Avenue, Columbus, Ohio, 43201, U.S.A.

(4) Western Research Institute, 365 N. 9th Street, PO Box 3395, Laramie, Wyoming 82071, U.S.A.

\begin{abstract}
Wastage of in-bed components in bubbling fluidized-bed combustors (FBC) has been a continuing problem. In response to this, there have been a number of attempts recently to develop testing techniques to help in the selection of resistant alloys and coating to resist wastage, and to determine the effect of critical process variables on the wastage. This paper summarizes what is known about the wastage in operating FBCs, to provide a basis for the qualification of the testing techniques.
\end{abstract}

\section{Introduction.}

Most commercial fluidized beds operate in either the bubbling mode or the circulating mode. This paper is concerned only with bubbling beds. A bubbling bed consists of a bubble phase having a low particle density, and a high particle density phase called the emulsion, which is often believed to be in a state of minimum fluidization. The bubbles are formed near the bottom of the bed and rise through it, growing in size and becoming fewer in number by coalescence; at the upper surface of the bed they collapse, in a manner which resembles bursting; fast-moving particles may be ejected in this event. The velocity of the rising bubble $U_{\mathrm{B}}$ increases with increasing bubble size, $d_{\mathrm{B}}$, and may be greater or less than the superficial gas velocity $U_{\mathrm{S}}$; however, the difference is not usually great.

The material in the bubble wake is relatively dense, and remains with the bubble, rising as the bubble rises. This is an important process in mixing the solids within the bed. The intrinsic solid mixing within the emulsion phase is by contrast very slow; these particles do move relative to one another, but the mean free path is small, typically less than the particle diameter.

The gas-solid mixing within a fluidized bed is very good, with excellent contact between the gas and the solid particles. In addition, the thermal conductivity is very good, and heat can be extracted from a combusting bed very efficiently by immersed tubular heat exchangers; but these may suffer considerable thinning as a result of mechanical and possibly chemical effects; in this paper this loss of section will be referred to generically as wastage. The wastage of in-bed surfaces is an important problem in practice; this can be either of the side-walls, or of the in-bed heat exchanger tubes. This paper addresses only the tube wastage problem. 
In-bed tube wastage is poorly understood. There is significant disagreement about the detailed mechanism of the process, particularly at elevated temperatures. It is clear that both the macroscopic flow characteristics in the bed and the detailed particle/tube interactions may be involved. There has been considerable success in studying macroscopic flow in beds using relatively small cold model fluidized beds. Glicksman [1] has written extensively on the importance of testing under circumstances where the experimental beds are properly scaled; if this is done, the behavior of the cold model appears to resemble that of the actual combustor very closely, and effects related to the flows in the bed can be accurately studied.

The velocity distribution for the particles within a fluidized bed, and its relationship to the other macroscopic velocities such as $U_{s}$, is currently not well-known. Boiarski [2] measured some relatively high velocities for a small fraction of the particles in a relatively small laboratory unit, but it is now believed that the measurements may have been at least partly in the splash zone. Generally, the particle velocities were somewhat less than the superficial velocity. Recently, Drennen et al. [3] developed an advanced probe for measuring particle impact velocities and mass flux at in-bed tube surfaces in a cold model. The particle impact velocities measured were in the range $0.3-1.2 \mathrm{~m} / \mathrm{s}$, but the authors comment that since a laser doppler method is used, measurements were only possible when there was dilute phase near the detector. The mass flux measurements did not suffer from this drawback, and values in the range $50-275 \mathrm{~kg} / \mathrm{s}-\mathrm{m}^{2}$ were measured. Further measurements have been reported by Podolski et al. [4].

An important, and little understood, phenomenon in fluidized beds is the appearance of a more-or-less periodic pressure pulse with a frequency somewhere between 0.5 and $2 \mathrm{~Hz}$. This frequency is apparently independent of many of the other variables. An early discussion of the effect was that of Turner and Irving [5], who suggested that the bursting of large bubbles at the upper surface of the bed resulted in the propagation of a pressure pulse downwards, which then interacted with the air flow through the distributor plate. Work at Oregon State University [6] using a cold model showed that there was a mechanical pulse with a similar frequency on in-bed tubes, and Vincent, Hart and Siddall [7] have also shown the same effect in the $20 \mathrm{MW}$ (e) Atmospheric Pressure Fluidized-Bed Combustor (AFBC) at Paducah. This effect has sometimes been attributed to the impact of rising bubble wakes on the lower surfaces of the tubes, but another possibility is the interaction of Turner acoustic pulses with the tubes: cold model studies have shown the opening and subsequent collapse of voids beneath the tubes in deep beds in a coordinated manner resembling cavitation which appears to be more in agreement with the acoustic pulse model than the bubble impact concept. Several investigators have shown video tapes of the impact of the bed on the underside of transparent tubes in cold beds using angled mirrors within the tubes, and it is quite clear that the impacts are directly related to the mechanical pulses. It is not yet clear whether the same is true in hot combustors, but the majority of the fluidized bed community believes this to be the case.

\section{The qualification of a test method.}

The aspects of wastage that are related to flow in the bed can probably be studied using appropriately designed cold models. However, there are aspects of wastage that appear to be related to the temperature, and perhaps the chemistry, of the actual combustor. There is also some reason to believe that an appropriate selection of material or surface treatment may reduce wastage. It is usually impractical, or at least uneconomic, to develop or evaluate new materials in real operating fluidized bed combustors. For this reason, it is important to 
develop test methods.

For any test procedure, it is not necessary that the test closely simulates the actual practical application which the test results are designed to address, since many of these details may be irrelevant to the damage process that is being studied, although in general, of course, there will be similarities in the detailed processes. What is important is that the test procedure satisfies a set of qualification criteria. This means that there has to be a set of practical results that are generally agreed, and that the test procedure must duplicate these. This then would allow the test procedure to be used for interpolative studies and, to a limited extent, extrapolative investigations. The principal objective of this paper is to suggest some criteria that might be used for this purpose, as a basis for discussion. In the following sections, the general experience in practice will be summarized, and a set of criteria will be proposed.

\section{Actual experience in fluidized bed combustors.}

The experience in practical fluidized bed combustors has been reviewed in some detail [8-11], and will not be repeated at length here. The more important results related to the qualification of a test procedure will be discussed.

For AFBCs, $U_{\mathrm{s}}$ is in the range $0.8-3.5 \mathrm{~m} / \mathrm{s}$, with AFBCs in the US operating nowadays at close to $1.5 \mathrm{~m} / \mathrm{s}$; the small UK units operate at somewhat higher velocities. The larger AFBC units in the US have beds which are typically of the order of 1-1.2 m deep, and most are forced circulation units with horizontal in bed tubes. Typically, the bed will have somewhere in the range of 5-8 layers of tubes, and these are mostly arranged in a triangular array, although in some cases the tubes are in a square or rectangular array. Smaller units have natural circulation, with sloping tube banks. These usually contain 2-4 layers. In the UK, the small industrial units mostly operate with shallow beds, typically $0.5 \mathrm{~m}$ deep. The bed material depends on the feedstock and the mode of operation. In the US, an important factor in the use of a fluidized bed is the ability of the unit to capture sulfur from the coal within the bed by using a sulfur acceptor, typically limestone. The bed then consists of calcium sulfate, unreacted lime (the limestone calcines rapidly), coal ash, and a small amount, usually less than $2 \%$ of char (the coal devolatilizes very quickly). The relative amounts depend on the sulfur content of the coal and its ash content. If there is a low sulfur, low ash coal, it may be necessary to add amounts of an inert material, typically river sand, to maintain the bed level. In the UK, sulfur capture is not usually a factor for the small industrial boilers, and the coal as supplied is low ash. The bed in these cases is largely sand.

Pressurized fluidized bed combustors (PFBCs) typically operate at approximately 11.5 MPa. The bed is much deeper, often 3-4 m, and the in-bed tube bundle is also much deeper. The acceptable velocity in PFBCs has been falling, largely as a result of wastage problems: originally, the unit at Grimethorpe was designed to operate at $12 \mathrm{fps}(3.7 \mathrm{~m} / \mathrm{s})$; but currently it is generally believed that the maximum acceptable velocity is in the range 0.8$1.2 \mathrm{~m} / \mathrm{s}$. The acceptor in PFBCs may be limestone or dolomite; inert material is not generally added. If there is a problem in maintaining bed depth, it is usually controlled by increasing the acceptor feed.

For all current FBCs, the mean bed particle size is close to $800 \mu \mathrm{m}$, although somewhat larger particles tend to accumulate in the bed; there may be a number of particles as large as $10 \mathrm{~mm}$ ("gravel"). 
3.1 OCCURRENCE OF WASTAGE. - An important fact is that many beds do not exhibit wastage at all. Ideally, a test procedure should give some clue as to why there should be this variation. For those beds that do suffer, the rates vary from $100 \mathrm{~nm} / \mathrm{h}$ to as high as $3000 \mathrm{~nm} / \mathrm{h}$. An acceptable rate would be of the order of $30 \mathrm{~nm} / \mathrm{h}$ : this would correspond to a loss of about 10 mils per year.

3.2 LOCATION. - Very nearly always, the wear is on the lower part of the in-bed tubes, although focal flow patterns may modify this, particularly for sloping tubes in natural circulation boilers. The wear on the lower part of the tubes appears in two patterns: one in which the maximum wear is at approximately $35^{\circ}$ on either side of the bottom, with the bottom wearing little if at all; and the second in which the wear is at a maximum at the bottom, decreasing to zero typically at $45^{\circ}$ or so. These patterns have been called "Class $\mathrm{A}$ " and "Class $B$ " by Stringer and Wright [12]. Several investigators have suggested that this difference in morphology may have an underlying mechanistic implication, for example as a result of a difference in the wear behavior of metal and oxide, or a difference related to the severity of the attack in an erosive/corrosive situation; but MacAdam and Stringer [13] have been able to show that it is possible to explain the appearance of these different morphologies on strictly hydrodynamic grounds. At the moment, therefore, it does not appear that it is a criterion that the test method should be capable of generating these two morphologies, but if the morphology were very different from either of these, the origin of the effect would need to be discussed.

In tube bundles with several rows, most wear occurs on the bottom row of tubes; the wear on the second row is at most one-third of this, and above that the wear is negligible. In the very deep tube bundles used in the pressurized fluidized bed combustor at Grimethorpe, a second maximum in the wastage appears in the upper part of the bundle [14]. These effects are related to hydrodynamic factors, and cannot be modeled in a small test.

3.3 Metal SuRfaCe TEMPERATURE $T_{\mathrm{m}}$. - General wastage does not ever appear to have been experienced by superheater tubes. There have been one or two occasions when superheater tubes have suffered damage, but these have been associated with the formation of energetic jets within the bed. The practical problem is entirely with the cooler evaporator tubes. In early testing at Grimethorpe, very severe tube wastage of the evaporator tubes was experienced. It was discovered that the wastage of different platens could be correlated with the riser temperature, which presumably was related to the metal temperature [15]. Within a relatively narrow temperature range, the wastage rate fell to low values as the temperature of the riser increased, implying the existence of a "transition temperature" $T_{\mathrm{w}}$ below which the wastage rate is high and above which the wastage rate is small. Subsequently, experiments were carried out at Grimethorpe to quantify this result. The full results have not yet been made public, but preliminary reports suggest [16] that the wastage is essentially absent for $T_{\mathrm{m}}>400-425^{\circ} \mathrm{C}$, equivalent to the surface temperature of utility evaporators. However, it is also stated that this result, and specifically the value of $T_{\mathrm{w}}$, depends on the tube material; but no data are presented for different materials to quantify this statement.

For industrial boilers, $T_{\mathrm{m}}$ will generally be below this value. The temperature dependence from room temperature up to just below $T_{\mathrm{w}}$ is thus of technical importance. There has been a long series of tests run on a small industrial-size boiler at TNO in the Netherlands. Generally, the results have been consistent with the Grimethorpe findings: at lower temperatures, there is a wastage rate which appears to be largely independent of temperature and of material (neglecting surface coatings). Recently, Tossaint, Rademakers and Norden [17] reported that reducing the fluidizing velocity from $2.6 \mathrm{~m} / \mathrm{s}$ to $2.1 \mathrm{~m} / \mathrm{s}$, and reducing the amplitude of the 
$\sim 1 \mathrm{~Hz}$ pressure pulse reduced $T_{\mathrm{w}}$ from $540^{\circ} \mathrm{C}$ to below $325^{\circ} \mathrm{C}$; a variety of steels - from plain carbon steel to $\mathrm{Fe}-12 \mathrm{Cr}-1 \mathrm{Mo}$ - behaved in essentially the same way. At $230^{\circ} \mathrm{C}$ the plain carbon steel wasted at a rate of $500 \mathrm{~nm} / \mathrm{h}$, which was about the same as in the earlier tests. The idea that the reduction in severity of conditions might lower $T_{\mathrm{w}}$ had been suggested by Jansson [18] but it is interesting that the low temperature wastage rate was not significantly affected.

Hanuda et al. [19] reported similar experience at the Wakamatsu $50 \mathrm{MW}(\mathrm{th}) \mathrm{AFBC}$, showing wastage rates of the order of $350 \mathrm{~nm} / \mathrm{h}$ for bottom row evaporator tubes at a temperature of approximately $335^{\circ} \mathrm{C}$ : the rate fell to very low values at $400^{\circ} \mathrm{C}$, remaining below $100 \mathrm{~nm} / \mathrm{h}$ up to $850^{\circ} \mathrm{C}$. A similar behavior has been observed in the wear pattern of an Omega-section tube exposed in the Georgetown University AFBC [20]. Along the cooled center-line of the flat, the wastage rate was approximately $310 \mathrm{~nm} / \mathrm{h}$, whereas in regions such as the fins, which were hotter because of the longer cooling path, the wastage was negligible.

A slightly different behavior was reported by Wright, Krause and Carlton [21]. In a 24 inch square cross-section coal-fired combustor, a water-cooled Type 316 stainless steel tube, with an estimated metal surface temperature below $250^{\circ} \mathrm{F}\left(121^{\circ} \mathrm{C}\right)$ was penetrated after $1100 \mathrm{~h}$. This is equivalent to a very severe wastage rate of close to $3000 \mathrm{~nm} / \mathrm{h}$. Some short-term tests $(144 \mathrm{~h})$ were then conducted with alloy specimens cooled to metal temperatures in the range $450-900^{\circ} \mathrm{F}$ (249-482 ${ }^{\circ} \mathrm{C}$ ). For Type 316 stainless steel, if one includes the low-temperature tube failure incident, the wastage rate did not vary by more than a factor of two or so over the whole range, although there was some indication of a fall-off above approximately $880^{\circ} \mathrm{F}$ $\left(460^{\circ} \mathrm{C}\right)$. However, the behavior of the other steels was significantly different. For a P9 steel (Fe-9Cr-1Mo), the rate increased with temperature at lower temperatures, and, indeed, if the data are extrapolated back, they imply that the wastage would be zero at $400^{\circ} \mathrm{F}\left(204^{\circ} \mathrm{C}\right)$; however, this extrapolation is almost certainly unjustified. Plain carbon and low alloy steel showed very accelerated losses at higher temperatures: at a temperature close to $800^{\circ} \mathbf{F}$ $\left(427^{\circ} \mathrm{C}\right.$ ) the metal loss was equivalent to a wastage rate of over $5000 \mathrm{~nm} / \mathrm{h}$. The authors suggested that the wastage rates were not only affected by the metal temperature, but also by a non-homogeneous flow pattern - "gulf streaming" - in the fluidized bed; this information should not be included in assessing temperature dependence in a normally fluidized bed.

3.4 TUbe material. - A very important result on this aspect is also from the early work at Grimethorpe [22]. Following the experience of very severe wastage on the bottom row of tubes, they were replaced by composite tubes with sections of a number of alloys: ranging from plain carbon steel, through low alloy steels, austenitic stainless steels, and Incoloy 800. The metal temperature was relatively low - perhaps $300-350{ }^{\circ} \mathrm{C}$ - and under these circumstances the wastage rates were essentially identical. As part of a long-term study of tube wastage in small AFBC industrial boilers, the Coal Research Establishment of British Coal [23] conducted $31000 \mathrm{~h}$ studies of erosion in a $0.6 \mathrm{~m}$ square bed; the tubes were cooled to metal temperatures in the range typically of $200-300^{\circ} \mathrm{C}$. A number of different materials were examined. The detailed results cannot be discussed here, but for the first and third tests the wastage rates of mild steel, a low alloy steel, Fe-9Cr-1 Mo, Type 410 ferritic stainless steel, and Types 310 and 321 austenitic stainless steels were in the range $150-1200 \mathrm{~nm} / \mathrm{h}$. A typical value would be $400 \mathrm{~nm} / \mathrm{h}$, and there was little systematic difference between the different alloys. Subsequently, there have been a number of efforts to develop improved materials or surface treatments. Blough reports that chromized surfaces wear less rapidly [24]. Results 
from the Georgetown University AFBC and Combustion Engineering agree with this. Combustion Engineering also report success using an overlay cladding called Extendalloy on the 160 MW (e) AFBC at TVA's Shawnee plant [25].

3.5 FEEDSTOCK. - There is little evidence to show that feedstock variations change the wastage behavior, although many investigators believe that this may explain some differences in behavior for otherwise similar units in practice. The singular exception is the experience at the $20 \mathrm{MW}$ (e) AFBC of TVA at Paducah, Kentucky [26]. Here, the wastage rate increased by a factor of ten following a relatively minor change in coal: the reason for this has been a matter for considerable debate. The two coals were very similar, but differed in their chlorine content, with the higher chlorine coal resulting in the greater wastage rate. However, subsequent testing has failed to confirm a large role for chlorine, and the British experience with relatively high chlorine coals has been adduced to suggest that chlorine content in itself is insufficient to explain the difference [27]. The possibility that the wastage rate difference might be due to other factors - the amount of quartz, the size distribution of the quartz, the effect of coatings on the bed particles - has been discussed by Wheeldon et al. [28], but the effects appeared to be factors of the order of 2 to perhaps 3 on the wastage rate, considerably less than the factor of 10 observed.

3.6 HEAT FLUX. - There has always been a debate in high-temperature oxidation and corrosion studies as to whether heat flux is important, and the same issue is relevant to the wastage situation. At the moment, there is no particular reason to believe that this is so, if only because cold-model beds give results which appear to be similar to those for cooled tubes in hot beds. However, the situation does need to be kept under review.

3.7 Deposition. - A topic which has seldom been discussed in the context of wastage is deposition on the in-bed tube surfaces. In coal-fired fluidized beds there are two deposition regimes. At low tube metal temperatures a black shiny deposit forms on the tubes. This is very thin; it most frequently forms predominantly on the lower tubes in a bundle and is more common over coal-feed ports. After cooling down, it will peel away from the tube surface within a relatively short time. It is typically high in carbon. At high metal temperatures, generally above $500^{\circ} \mathrm{C}$, a quite different deposit forms [29]. This contains very little carbon. It is very dense: the porosity is too low to be measured. It appears to be formed of an accretion of very small particles, and the overall composition is fairly similar to that of the bed material. The deposit can under some circumstances be quite thick, of the order of 1 $5 \mathrm{~mm}$; more usually it is close to $100 \mu \mathrm{m}$. The deposits are very adherent, particularly to the oxide on the metal; after cooling, sections of the deposit and scale separate from the tube surfaces together, the separation occurring at the oxide/scale interface with the oxide/deposit interface appearing strong [30]. This does not necessarily imply that the deposit forms on an oxidized surface, since it is possible for the oxide to grow beneath the deposit layer. If there is a deposit on the metal surface, it is important to note that metal loss by wastage cannot be taking place, either by direct metal removal or by oxide removal. If there is metal loss, it either preceded the deposit formation, or the deposit is periodically forming and detaching. In analyzing the temperature dependence of wastage, the role of deposition cannot be neglected. Does deposition prevent erosion, or does deposition only occur when, for some other reason, erosion ceases? Deposition can also occur on the bed particles, as mentioned above, and this may have an effect on wastage. This aspect is currently under investigation. 


\section{Qualification criteria.}

On the basis of the practical experience described above, it appears that there are three reasonably clear results that can act as the basis for qualification criteria for test procedures. These are: the rate of wastage, the temperature dependence of the wastage rate, and the effect of alloy composition. There are a number of other aspects which one may wish to examine to assess the degree to which the test damage processes resemble those in practice, but (certainly at the present stage of knowledge) these are insufficiently well-defined in the practical experience to act as qualification criteria in the sense defined above.

4.1 WASTAGE RATE. - It is probably important to attempt to achieve a wastage rate that is reasonably close to that in practice. This is certainly true if chemical effects are to be included, since it is difficult to accelerate two independent effects to the same degree. As mentioned above, $30 \mathrm{~nm} / \mathrm{h}$ would be an entirely acceptable rate of surface loss. While rates as high as $3000 \mathrm{~nm} / \mathrm{h}$ have been reported, this may be so severe as to conceal effects of importance. We propose that a rate somewhere in the range 300-1000 $\mathrm{nm} / \mathrm{h}$ should be the target.

4.2 TEMPERATURE DEPENDENCE. - The most obvious result from practice is the abrupt drop in wastage at some transition temperature $T_{\mathrm{w}}$, which may be close to $400^{\circ} \mathrm{C}$ for relatively severe conditions, and probably lower for mild conditions or more resistant materials (this assumes that there are more resistant materials: at the moment, the best evidence for this is the as yet unsubstantiated comment from the Grimethorpe work).

For $T_{\mathrm{m}}<T_{\mathrm{w}}$ the temperature dependence of the wastage rate is small.

4.3 EFFECT OF MATERIAL. - The evidence shows that for $T_{\mathrm{m}}<T_{\mathrm{w}}$ there is essentially no difference between plain carbon steels and austenitic stainless steels. The transition temperature may be material dependent, but in the absence of concrete evidence this could not be used as a criterion; the eventual release of the Grimethorpe data may allow a criterion to be defined.

\section{Summary and conclusions.}

Wastage of in-bed tubes is a technically important problem for fluidized bed combustion systems. Some of the contributions to the wastage are related to the hydrodynamics of the bed, and these can be dealt with using appropriately scaled cold beds. Some effects appear to be due to temperature, deposition, and perhaps chemical interactions. These cannot be studied in cold beds, and require the development of test procedures, one important role for which is to give guidance in materials selection. It is proposed that a test procedure for evaluating materials for fluidized beds should satisfy four qualifying criteria. 1) The wastage rate should be reasonable, typically in the range $300-1000 \mathrm{~nm} / \mathrm{h}$; 2) There should be a transition metal surface temperature $T_{\mathrm{m}}=T_{\mathrm{w}}$ above which the wastage rate drops to very low values. In order to achieve this, it may be necessary for the test procedure also to address the issue of deposition; 3) The wastage rate should show little dependence on temperature for $T_{\mathrm{m}}<T_{\mathrm{w}}$; 4) The wastage rates for plain carbon steels, low alloy ferritic steels, and austenitic steels such as Type 304 should be essentially the same for $T_{\mathrm{m}}<T_{\mathrm{w}}$, although $T_{\mathrm{w}}$ may be different. 


\section{References}

[1] Glicksman L.R., Chem. Eng. Sci. 39 (1984) 1373.

[2] BOIARSKI A.A., Testing, Identification and Evaluation of Advanced Experimental Materials and Coatings in the Design Conditions for Simulated Fossil Fuel Power Cycle Conditions - Task 2, Battelle Report NTIS No. FE-2325-19 (1978).

[3] Drennen J.F., Howard D.A., Hocking W.R., Botros P., Proc. 1989 Intl. Conf. on Fluidized Bed Combustion, A.M. Manaker Ed. (American Society of Mechanical Engineers, New York, N.Y., 1989) p. 457.

[4] Podolski W.F., LyCzkowski R.W., MonTrone E., Drennen J., AI Y.H., ChaO B.T., 1991 Fluidized Bed Combustion - Clean Energy for the World, E.J. Anthony Ed. (American Society of Mechanical Engineers, New York, N.Y., 1991) p. 609.

[5] Turner M.J., Irving D., Proc. 7th Intl. Conf. on Fluidized Bed Combustion, Vol. 2, US. DOE/METC/83-48 (1983) p. 831.

[6] KENNEDY T.C., A Study of Forces on Immersed Tubes in Fluidized Beds, Final Report to EPRI under Research Contract RP718-2, Report No. CS-1542 (Electric Power Research Institute, Palo Alto, California, USA, 1980).

[7] Vincent R.Q., HaRT D.E., Siddall W.F., Proc. 1987 Int. Conf. on Fluidized Bed Combustion, J.P. Mustonen Ed. (American Society of Mechanical Engineers, New York, N.Y., 1987) p. 567.

[8] STRINGeR J., Proc. 1987 Int. Conf. on Fluidized Bed Combustion , J.P. Mustonen Ed. (American Society of Mechanical Engineers, New York, N.Y., 1987) p. 685.

[9] STRinger J., Stallings J.W., Wheeldon J.W., Proc. 10th Intl. Conf. on Fluidized Bed Combustion: FBC - Technology for Today, A.M. Manaker Ed. (American Society of Mechanical Engineers, New York, N.Y., 1989) p. 857.

[10] Electric Power Research Institute, Workshop on FBC Materials Issues, (Port Hawkesbury, Nova Scotia, Canada, 1985).

[11] Electric Power Research Institute, Workshop Proceedings, Wastage of In-Bed Surfaces in Fluidized-Bed Combustors (Argonne National Laboratory, Argonne Illinois, 1987).

[12] STRINGER J. WRight I.G., Paper 1 in Ref. [11].

[13] MACADAM S.S., STRINGER J., to be published.

[14] NCB (IFA Grimethorpe Ltd., Reports Nos. GEF/U/82 21 (1982) and GEF/U/83/5 (1984).

[15] Minchener A.J., Stringer J., Brooks S., Lloyd D.M., SWift W.M., ANDERSON J.S., MAINHARDT P.J., Proc. Eighth Int. Conf. on Fluidized-Bed Combustion, Vol. II (U.S. Department of Energy, Morgantown Energy Technology Center DOE/METC85/6021, Morgantown, West Virginia, USA, 1985) p. 760.

[16] MEAdowCroft D.B., MONTRONE E.D., OAKEY J.E., STOTT J., FBC Technology and the Environmental Challenge (Adam Hilger, Bristol, UK, 1991) p. 105.

[17] TOSSAint H.H.J., RAdemakeRs P.L.F., VAN NORden P.P., Paper 2.3 in Ref. [11].

[18] JANSSON S.A., Paper 4.8 in Ref. [11]

[19] Hanuda T., Simizu T., Fukuda Y., Yamasaki H., Koga S., NONAKa K., Paper 2.6 in Ref. [11].

[20] Sethi V.K., WRight I.G., DOOLey R.B., StallingS J.W., STRINGER J., WHEeldON J.M., Proceedings of the 11 th Conf. on Fluidized Bed Corrosion (1991) p. 737.

[21] WRight I.G., Krause H.H., CARLTON H.E., J. Mat. Energ. Syst. 2 (1980) 33.

[22] See the Reports in Ref. [14]. See also STRINGER J., Druckaufgeladene Wirbelschichtfeuerung (VDI Berichte 715, VDI Verlag, Düsseldorf, Germany, 1989) p. 57. 
[23] Coal Research Establishment of British Coal, Minimising Erosion in Coal-Fired Boilers, Final Report on ECSC Project No. 7220-ED/808 (April 1989).

[24] Blough J.L., Paper 6.2 in Ref. [11].

[25] CANONICO D.A., Paper 6.3 in Ref. [11].

[26] Vincent R.Q., Poston J.M., Smith B.F., Proc. 1987 Int. Conf. on Fluidized Bed Combustion, J.P. Mustonen Ed. (American Society of Mechanical Engineers, New York, N.Y., 1987) p. 672.

[27] Vincent R.Q., MANAKER A.M., Chlorine in Coal, J. Stringer, D.D. Banerjee Eds. (Elsevier Science Publishers, Amsterdam, The Netherlands, 1991) p. 389;

SETHI V.K., WRIGHT I.G., ibid., p. 417.

[28] Wheeldon J.M., Stallings J.W., Sethi V.K., Wright I.G., Proc. Corrosion-Erosion Wear of Materials at Elevated Temperatures, A.V. Levy Ed. (National Association of Corrosion Engineers, Houston, Texas, 1991) p. 22-1.

[29] OAKEY J.E., MiNCHENER A.J., STRINGER J., J. Inst. Energ. 62 (1989) 208.

[30] Wright I.G., Rocazella M.A., NAGarajan V., Paper 5.5 in Ref. [11]. 